\title{
DESCRIÇÃO DO GÊNERO "DEFESA" DE TRABALHOS DE GRAU: TIPIFICAÇÃO E SINGULARIDADE
}

\begin{abstract}
Maria Auxiliadora Bezerra*
Resumo: Os objetivos deste artigo são descrever o gênero defesa de trabalhos, identificando formas tipificadas, características de defesa de dissertação e de tese, e demonstrar que não se constituem gêneros diferentes, pois são retomadas formas de agir idênticas, esperando-se obter os mesmos efeitos: obtenção de título acadêmico. Para isso, analisamos, à luz de estudos sociorretóricos, oito defesas audiogravadas e respostas de professores e de pós-graduandos à pergunta "O que é defesa de dissertação/tese?". As análises demonstram presença de formas tipificadas idênticas (como exposição de texto-resumo, questionamentos, respostas) e dados singulares (situação distensa, informalidade e uso de palavras denotando aproximação), possibilitando algumas conclusões: "defesa de trabalho de grau" pode ser utilizada como uma expressão superordenada; singularidades dependem mais dos participantes da interação social onde ocorre a defesa do que da ação social de defesa de trabalbo e a especificação "dissertação"/"tese" reflete os gêneros escritos, que originam sua defesa oral.

Palavras-chave: Gênero. Dissertação. Tese. Defesa.
\end{abstract}

\section{INTRODUÇÃO}

As pesquisas sobre gêneros textuais possibilitam o conhecimento de ações sociais discursivas, descrevendo-os em seus aspectos recorrentes, mas também em suas particularidades, visto que os gêneros são multidimensionais e fluidos. Assim, gênero só se constitui enquanto tal estando incluído em práticas sociais - caracterizando-se, portanto, como fatos sociais - e comportando formas textuais padronizadas, tipificadas, que se repetem em circunstâncias semelhantes entre si (BAZERMAN, 2006). E estudá-lo significa mobilizar conhecimentos sobre seus usos sociais, sobre as interações realizadas no ato de comunicação e sobre os itens formais delas decorrentes.

Nessa perspectiva, nosso objetivo é descrever aspectos retóricos do gênero defesa de trabalhos de grau, identificando formas tipificadas e

\footnotetext{
* Professora da Universidade Federal de Campina Grande, Paraíba. Doutora em Linguística. Email: cidabezerra@uol.com.br.
} 
singulares (características de defesa de dissertação e de tese), com o intuito de demonstrar que não se constituem gêneros diferentes, visto que são retomadas formas de agir idênticas, esperando-se obter os mesmos efeitos: aprovação e obtenção de um título acadêmico.

\section{GÊNERO COMO AÇÃO SOCIAL}

O conjunto de teorias que abordam gênero em múltiplos enfoques mostra a importância desse conceito no cenário dos estudos da linguagem e a dificuldade de analisá-lo, dada a sua plasticidade e dinamicidade. Embora sejam explorados aspectos diversos do gênero, sua natureza social se destaca, tendo em vista a sua imbricação nas atividades culturais e sociais e o próprio caráter social da linguagem (componente que o corporifica). Por isso, Miller define gêneros como formas de ação (1984) e artefatos culturais (1994), baseando-se no fato de que eles se constroem nas interações sociais e se situam em um tempo e um espaço definido, de tal forma que, ao mesmo tempo em que são flexíveis, são também tipificados, a ponto de serem reconhecidos como tal, em situações semelhantes àquelas em que funcionam. Essas características de flexibilidade e estabilidade, à primeira vista contraditórias, nos levam a entender que eles estão enraizados em práticas sociais e, como essas mudam e evoluem, os gêneros também se modificam e se reestruturam, atendendo às necessidades de seus usuários e, ao mesmo tempo, criando necessidades sociais.

Para ilustrar o que foi dito, citamos Miller (2004), em seu estudo sobre blog. Os primeiros blogs (1998) foram construídos por trabalhadores da indústria tecnológica (designers e programadores) para compartilharem informações de seu interesse, de forma rápida, em ordem cronológica e com comentários. Um ano depois (1999), surgem portais oferecendo instruções para criação e uso de blogs, sem que o usuário fosse experiente nesse assunto. E a estimativa era de que, no final de 2004 (ano em que a autora publicou seu trabalho) houvesse 10 milhões de blogs. Nesses poucos anos, o conteúdo semântico, as características formais e a ação pragmática dos blogs se modificaram consideravelmente, chegando, por exemplo, a um limite tênue entre a vida pública e privada de seus usuários. Em outras palavras, percebemos a criação de um gênero para atender aos interesses dos especialistas na 
área de tecnologia e sua influência em diversos grupos sociais, adaptando-se e modificando-se, conforme os atos praticados de forma recorrente. Assim, conforme Marcuschi (2005, p. 24), é pela ação que os sentidos sociais dos gêneros são produzidos e reproduzidos e as suas estruturas são criadas.

Também apoiado no aspecto social, Bazerman define gênero como um fato social. Para esse autor, fatos sociais "são as coisas que as pessoas acreditam que sejam verdadeiras e, assim, afetam o modo como elas definem uma situação." (BAZERMAN, 2005, p. 23). Ou seja, tudo aquilo que as pessoas acham que é real é um fato social e, assim, elas passam a agir baseadas nessa verdade. Essa crença atinge inclusive a linguagem: os fatos sociais afetam o que é dito pelas pessoas e a força que isso que foi dito tem, pois, acreditando numa determinada verdade, os participantes de um grupo social terão comportamento compatível com essa verdade, esperando resultados satisfatórios.

Com isso, o locutor recorre a formas repetidas de agir em determinadas situações, garantindo, assim, a realização de certos atos. $\mathrm{O}$ sucesso desse procedimento faz com que, em ocasiões semelhantes, ele seja retomado e, dessa forma, construam-se formas tipificadas, consequentemente, reconhecíveis, possibilitando que o que se pretende realizar seja mais facilmente entendido. A esse processo de padronizar formas de comunicação e de situações nas quais os interlocutores se encontram, Bazerman (2005, p. 29) chama de tipificação: "Esse processo de mover-se em direção a formas de enunciados padronizados, que reconhecidamente realizam certas ações em determinadas circunstâncias, e de uma compreensão padronizada de determinadas situações, é chamado de tipificação."

O resultado da tipificação são os gêneros, ou seja, "as formas de comunicação reconhecíveis e autorreforçadoras" (BAZERMAN, 2005, p. 29), que são utilizadas em determinadas situações, para se obter determinado efeito, visto que em situações anteriores ocorreu efeito idêntico. A natureza autorreforçadora do gênero não impede o aparecimento de uma característica singular, que particulariza um determinado ato de fala, favorecendo uma mudança na forma tipificada conhecida. No entanto, se essa singularidade causa o efeito desejado pelo locutor, ela passará possivelmente a fazer parte do gênero, tipificando-se. 
Essa reflexão encontrada em Bazerman (2005) relaciona-se à definição de gêneros do discurso dada por Bakhtin ([1979] 1997, p. 279): "tipos relativamente estáveis de enunciados", elaborados por cada esfera da atividade humana, utilizando-se da linguagem. Ou seja, mesmo constituindo-se formas padronizadas, os gêneros se modificam em consonância com os grupos sociais e suas atividades.

A concepção de gênero defendida por Bazerman (2005) assim como por Miller $(1984,1994,2005)$ ultrapassa os limites puramente formais e linguísticos do texto (que são seus constituintes, mas não únicos), visto que é uma ação social tipificada. Nesse sentido, os gêneros contribuem para interpretarmos ou construirmos uma ação social discursiva, visto que, ao lançarmos mão de um determinado gênero, estamos lançando mão de formas padronizadas, que nos ajudam a lidar com a situação apresentada, mas também estamos lançando mão do papel que essa situação desempenha no grupo social, do significado que ela representa para as pessoas, sem tornar o gênero estático e cristalizado, para não esvaziar seu sentido.

Do ponto de vista da análise, o gênero precisa ser estudado na sua relação com as práticas sociais, os aspectos cognitivos, os interesses, as relações de poder, as tecnologias, as atividades discursivas, e no interior da cultura do grupo onde ele funciona (MARCUSCHI, 2005).

\section{PROCEDIMENTOS METODOLÓGICOS}

Os dados empíricos para nossa análise são oriundos de duas fontes interligadas: uma é o conjunto de cinco defesas de dissertação e três de tese, audiogravadas (apenas uma tese foi filmada) e/ou registradas em anotações de campo pela pesquisadora, que fazia parte ora da banca examinadora, ora do público presente nos eventos de conclusão dos cursos de mestrado ou de doutorado; e a outra fonte são respostas dadas por nove pessoas envolvidas com a Pós-graduação, que estavam também nesses eventos (e eram informadas sobre nossa pesquisa a respeito de gêneros textuais), à pergunta "o que é uma defesa de dissertação/tese?". Essa pergunta foi feita minutos antes, no intervalo ou depois das defesas, que constituem o conjunto de dados citado acima. Um detalhamento desses dados empíricos pode ser visto nos quadros $1 \mathrm{e}$ 2, abaixo. 


\begin{tabular}{|c|c|c|c|c|c|c|c|}
\hline Nível & Qtde & Temas & IES* & Programa & Defesa & $\begin{array}{l}\begin{array}{l}\text { Duração } \\
\text { (aprox) }\end{array} \\
\end{array}$ & $\begin{array}{l}\text { Formas } \\
\text { de registro }\end{array}$ \\
\hline \multirow{5}{*}{ 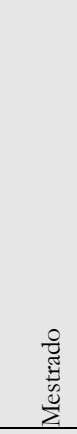 } & 01 & $\begin{array}{l}\text { Alfabetização } \\
\text { de adultos e } \\
\text { idosos }\end{array}$ & UFPB & Educação & $\begin{array}{l}\text { Nov. } \\
2006\end{array}$ & $\begin{array}{l}2 \mathrm{~h} \mathrm{e} \\
30 \mathrm{~min}\end{array}$ & $\begin{array}{l}\text { Gravação } \\
\text { em áudio }\end{array}$ \\
\hline & 01 & $\begin{array}{l}\text { Escrita } \\
\text { acadêmica }\end{array}$ & \multirow{4}{*}{ UFCG } & $\begin{array}{l}\text { Linguagem } \\
\text { e Ensino }\end{array}$ & $\begin{array}{l}\text { Dez. } \\
2006\end{array}$ & $2 \mathrm{~h}$ & $\begin{array}{l}\text { Gravação } \\
\text { em áudio }\end{array}$ \\
\hline & 01 & $\begin{array}{l}\text { Transposição } \\
\text { didática }\end{array}$ & & $\begin{array}{l}\text { Linguagem } \\
\text { e Ensino }\end{array}$ & $\begin{array}{l}\text { Dez. } \\
2006 \\
\end{array}$ & $2 \mathrm{~h}$ & $\begin{array}{l}\text { Gravação e } \\
\text { anotações }\end{array}$ \\
\hline & 01 & $\begin{array}{l}\text { Transposição } \\
\text { didática }\end{array}$ & & $\begin{array}{l}\text { Linguagem } \\
\text { e Ensino }\end{array}$ & $\begin{array}{l}\text { Dez. } \\
2006\end{array}$ & $2 \mathrm{~h}$ & $\begin{array}{l}\text { Gravação } \\
\text { em áudio }\end{array}$ \\
\hline & 01 & $\begin{array}{l}\text { Ensino de } \\
\text { vocabulário }\end{array}$ & & $\begin{array}{l}\text { Linguagem } \\
\text { e Ensino }\end{array}$ & $\begin{array}{l}\text { Nov. } \\
2006\end{array}$ & $2 \mathrm{~h}$ & $\begin{array}{l}\text { Gravação e } \\
\text { anotações }\end{array}$ \\
\hline \multirow{3}{*}{\begin{tabular}{l}
0 \\
$\frac{\pi}{\pi}$ \\
0 \\
\multirow{0}{0}{} \\
0
\end{tabular}} & 01 & Leitura & UFPB & Letras & $\begin{array}{l}\text { Jun. } \\
2006\end{array}$ & $5 \mathrm{~h}$ & $\begin{array}{l}\text { Gravação } \\
\text { em vídeo }\end{array}$ \\
\hline & 01 & Gênero textual & UFAL & Letras & $\begin{array}{l}\text { Set. } \\
2006\end{array}$ & $4 \mathrm{~h}$ & Anotações \\
\hline & 01 & Gênero textual & UFPE & Letras & $\begin{array}{l}\text { Dez. } \\
2006\end{array}$ & $4 \mathrm{~h}$ & $\begin{array}{l}\text { Gravação } \\
\text { em áudio }\end{array}$ \\
\hline
\end{tabular}

Quadro 1 - Descrição das defesas que compõem a primeira fonte de dados empíricos.

*Legenda: UFPB (Universidade Federal da Paraíba); UFCG (Universidade Federal de Campina Grande); UFAL (Universidade Federal de Alagoas); UFPE (Universidade Federal de Pernambuco).

As dissertações e teses, defendidas em 2006, embora realizadas em Programas de Pós-graduação diferentes (Educação, Letras e Linguagem e Ensino), abordam assuntos relativos à linguagem, quer no plano de seu uso (gêneros textuais 'piada', na UFAL, e 'parecer pedagógico', na UFPE), quer no plano de seu ensino (alfabetização e leitura, na UFPB; escrita acadêmica, transposição didática e ensino de vocabulário, na UFCG). 


\begin{tabular}{|l|l|l|l|l|}
\hline Sujeitos & Instituição & Qtde & $\begin{array}{l}\text { Data das } \\
\text { respostas }\end{array}$ & $\begin{array}{l}\text { Formas } \\
\text { de registro }\end{array}$ \\
\hline \multirow{2}{*}{ Mestrandos } & UFPB & 01 & Nov. 2006 & \multirow{3}{*}{ Anotações } \\
\cline { 2 - 4 } & UFCG & 03 & Dez. 2006 & \multirow{3}{*}{ Anotações } \\
\hline \multirow{2}{*}{ Doutorandos } & UFAL & 01 & Set. 2006 & \multirow{3}{*}{ Anotações } \\
\cline { 2 - 4 } & UFPE & 01 & Dez. 2006 & \\
\hline \multirow{3}{*}{ Professores de Pós-graduação } & UFCG & 01 & Nov. 2006 & \\
\cline { 2 - 4 } & UFAL & 01 & Set. 2006 & \\
\cline { 2 - 4 } & UFPB & 01 & Nov. 2006 & \\
\hline
\end{tabular}

Quadro 2 - Descrição do segundo conjunto de dados empíricos

Os sujeitos que responderam à única pergunta feita (“O que é uma defesa de dissertação/tese?”, citada antes) foram quatro mestrandos, dois doutorandos e três professores de pós-graduação de instituições variadas (conforme se vê no quadro 2), que estavam, respectivamente, fazendo suas defesas e participando da banca ou da plateia.

A partir desses dois conjuntos de dados empíricos, pudemos construir os dados de análise, à luz das contribuições teóricas de Miller (1984, 1994), de Bazerman (2005, 2006) e de Marcuschi (2005), entre outros: aspectos sociais e retóricos do gênero defesa.

\section{DESCREVENDO 'DEFESA' COMO GÊNERO}

\section{1 'Defesa' como parte de um conjunto de gêneros}

De acordo com Miller (1984), o fato de um tipo de discurso ou uma ação comunicativa adquirir um nome em um determinado contexto ou comunidade é sinal de que ele está funcionando como um gênero. Com base nessa afirmação, reconhecemos como gênero a ação social que constitui um dos pré-requisitos para a conclusão de curso de pósgraduação stricto sensu (mestrado e doutorado) e que inclui um texto oral que o mestrando ou o doutorando constrói, expondo de forma resumida seu trabalho de pesquisa. Essa ação é chamada de "defesa" de dissertação ou de tese, caso se esteja concluindo o mestrado ou o doutorado, respectivamente. 
Essa defesa faz parte de um conjunto de gêneros produzidos por alguém exercendo o papel de aluno de pós-graduação. Esse conjunto se inicia no ato de inscrição para seleção do mestrado/doutorado, quando o candidato preenche o formulário de inscrição, o que lhe dá o direito de participar dessa seleção. E ele se amplia com a realização da prova escrita, no período da seleção, com a entrevista (no caso de o candidato ter sido aprovado na prova anterior), com o preenchimento do formulário de matrícula, após aprovação e classificação, com as anotações de aulas, os trabalhos das disciplinas, artigos escritos para apresentação em eventos científicos e/ou publicação em revistas ou anais, o projeto de pesquisa, discussões sobre a dissertação/tese com o orientador, o texto para o exame de qualificação, o acordo com o orientador sobre a composição da banca examinadora, a dissertação/tese, o resumo a ser apresentado no dia da defesa e a exposição oral nesse dia.

Esse conjunto de gêneros associado a outros constituem um sistema de gêneros (BAZERMAN, 2005) característico de uma situação acadêmica (a qual conta com muitos outros sistemas de gêneros, como, por exemplo, o do setor administrativo, o da sala de aula, o do colegiado do curso e outros). Conhecendo-se esse sistema, pode-se identificar um conjunto de atividades desenvolvidas de acordo com uma determinada sequência, no programa de pós-graduação onde o estudante se encontra, pois ele faz parte do sistema de atividades desse programa. Isso é o que podemos ilustrar com o exemplo 1 abaixo, em que o coordenador do Programa de Pós-graduação em Educação (UFPB) dá início à sessão de defesa de uma dissertação, expondo como se encontra o Programa e quantas defesas estão ocorrendo simultaneamente.

Ex.1

Co.M1-UFPB: /.../ essa turma de 2004 passou por muitos problemas de ordem é...é...digamos assim...institucionais até...né? porque a gente aderiu à greve e aí o pessoal ficou com as disciplinas ainda penduradas...essa coisa assim...então...de fato...de modo que nós não... num... não vamos ter $100 \%$...né? de defesa no prazo regimental institucional e a gente vai decidir então daqui a pouco no colegiado o que é que a gente vai fazer com o pessoal que não...não...não vai conseguir defender até $\mathrm{o}$ dia de 
amanhã/.../ só pra você ter uma ideia...amanhã...nós teremos DEZ defesas no Programa.

Pelo depoimento do Coordenador, podemos identificar um frame que organiza as atividades do Programa: os mestrandos e doutorandos devem cursar todas as disciplinas previstas, em um prazo estabelecido, para, por fim, defenderem a dissertação ou a tese; no caso de não cumprimento desse prazo, o colegiado do curso se reúne para tomar uma decisão a esse respeito. Foi isso que ocorreu com a turma de mestrandos de 2004: a greve dos professores (que suspenderam as aulas) impediu que os alunos concluíssem no tempo previsto suas disciplinas (“...a gente aderiu à greve e aí o pessoal ficou com as disciplinas ainda penduradas...") e chegassem ao prazo final do mestrado sem as dissertações concluídas ("...a gente vai decidir então daqui a pouco no colegiado o que é que a gente vai fazer com o pessoal que não...não...não vai conseguir defender até o dia de amanhã...”).

Essas atividades se realizam através de um conjunto de gêneros: as disciplinas, com programas de conteúdo, diário de classe, exposições orais, fichamentos, discussões, monografia e outros; a reunião do colegiado, com convocação, pauta, ata, lista de presença, exposição oral, discussão, decisão tomada; o acompanhamento da vida acadêmica dos alunos, com trabalhos acadêmicos, dissertação, defesa de dissertação, declarações, certificado... Dessa forma, o gênero 'defesa' de dissertação ou tese, tendo lugar no final da vida acadêmica do pós-graduando, indica que os gêneros adequados a cada trabalho do sistema de atividades foram realizados, contribuindo com a eficiência desse sistema.

\section{2 'Defesa' como forma tipificada}

Caracterizar os gêneros no âmbito das ações sociais e considerálos como "um recurso que nos ajuda a localizar nossa ação discursiva em relação a situações altamente estruturadas" (BAZERMAN, 2006, p. 29) fazem com que entendamos por que a defesa é reconhecida como tal, embora apresente traços organizacionais e textuais diferentes entre um Programa de Pós-graduação e outro. Comparando a defesa de tese realizada na UFAL (Dou2-UFAL) com a realizada na UFPE (Dou3- 
UFPE), sobre o mesmo tema (gêneros textuais), verificamos que, para os dois doutorandos abordados, a defesa é a apresentação oral do trabalho final para ser avaliado por especialistas, conforme podemos ler no exemplo 2, a seguir.

Ex. 2

A) P- o que é defesa de tese pra você?

Dou2-UFAL: é uma exposição oral do trabalho feito, para uma banca avaliar... é... é...uma situação muito estressante...você passa o tempo todo escrevendo um trabalho... e a gente não sabe se a banca vai gostar... tem membro da banca que derruba o trabalho da gente...

B) Dou3-UFPE: é o momento que a gente mostra o trabalho final... a pesquisa foi feita... os dados foram analisados e a banca analisa... pergunta... você fica nervosa... num sabe se tão gostando... ou não...

A pergunta do exemplo $2 \mathrm{~A}$ foi realizada antes de a defesa ter início, enquanto a do $2 \mathrm{~B}$ ocorreu no intervalo dado após a arguição do segundo examinador. Em 2B, mesmo já tendo havido a participação de dois examinadores, exatamente os convidados de outras instituições (diferentes da instituição a que o doutorando está vinculado), a resposta dada não foi influenciada por esse momento, já que algumas questões apresentadas por esses examinadores indicavam não aceitação do que tinha sido realizado na tese e o doutorando declara: "você fica nervosa... num sabe se tão gostando... ou não...” Em outras palavras, se já havia a indicação de que algumas afirmações na tese não eram consensuais, o doutorando não as levou em conta ao formular sua resposta, do contrário, não teria demonstrado dúvida: "num sabe se tão gostando... ou não...”

A resposta de $2 \mathrm{~A}$ é idêntica à de $2 \mathrm{~B}$ : o que predomina é a ação social, a interação da banca com os doutorandos e o processo de avaliação ("exposição oral do trabalho feito, para uma banca avaliar...; o momento que a gente mostra o trabalho final... num sabe se tão gostando... ou não..."). O mesmo ocorre com os três professores que 
responderam a nossa pergunta, conforme podemos constatar no exemplo 3, a seguir, em que são mostradas suas respostas apontando para a tipificação da defesa.

Ex.3

A) P-o que é defesa de tese/dissertação pra você?

Pro1-M2-UFCG: é a apresentação da pesquisa que o mestrando fez... os resultados... o ritual exigido... a banca... as perguntas...

B) Pro2-D2-UFAL: é o momento que o mestrando... doutorando expõe... defende sua pesquisa pra banca e pro público... responde a arguição e recebe aprovação...

C) Pro3-M1-UFPB: é o momento mais importante do mestrando... ele vai defender o que fez... sua pesquisa... esclarecer as dúvidas da banca...

Nas três respostas, percebemos uma ação social que se realiza numa circunstância determinada e de forma recorrente, daí ser tipificada ("apresentação de pesquisa... o ritual... a banca; momento que o mestrando expõe... defende sua pesquisa pra banca e pro público; momento mais importante do mestrando... defende o que fez... esclarecer dúvidas da banca...”). Essa ação tipificada, ou seja, esse gênero, contribui para se interpretar outras ações semelhantes: veja-se que as respostas foram dadas por professores e alunos de instituições diversas, localizadas em cidades diferentes, em defesas de dissertação e/ou de tese, que mobilizam conhecimentos anteriores semelhantes, capazes de orientá-los a reconhecerem o gênero defesa. Além disso, essa ação também contribui para se construir novas ações acadêmicas (outros momentos em que uma defesa for ser realizada por outros mestrandos ou doutorandos, com a participação de outros professores, como membros da banca). Para ser identificada como tal, uma defesa deve seguir algumas características cristalizadas.

Em relação ao aspecto organizacional da defesa, observamos que, em geral, o pós-graduando responde ao examinador, após este ter concluído seus comentários e perguntas. É o que vemos em sete das oito defesas em análise: os examinadores informam que vão fazer seus 
comentários ou perguntas em blocos predefinidos por eles e, em seguida, passam a palavra ao pós-graduando, para suas respostas. Podemos ilustrar esse procedimento com exemplos de defesa de dissertação e de tese:

\section{Ex.4}

E2-M2-UFCG: /.../ fiz aqui algumas observações de ordem formal...das características do texto em si... algumas de ordem metodológica... e outras de ordem teórica... né?...

E1-D1-UFPB: /.../ vou olhar seu trabalho de forma prospectiva...pra frente /.../ fazer questões que seu trabalho faz emergir... e portanto provavelmente se você não quiser dar respostas... quiser só comentar... pode ficar bem à vontade... e depois não... vou fazer questões pontuais... de concordância e discordância... e aqui acolá talvez fosse interessante você explicar o porquê...

Com essa orientação, os participantes dessa ação social reforçam a sua tipificação. Esse modelo recorrente parece ser o esperado pelos mestrandos e doutorandos cujas defesas estamos analisando, pois, na única ocasião em que ele não foi seguido, o mestrando perguntou ao examinador se poderia responder após a primeira questão posta. $\mathrm{O}$ exemplo 5 ilustra o que foi dito.

\section{Ex.5}

E1-M2-UFCG: a propósito queria fazer uma pergunta... é um período de coleta muito grande...quais foram os critérios que levaram você a fazer o recorte? Você pegou o período e selecionou o que a professora usou na sala de aula... bem pode ser minha leitura... mas não está claro... eu conheci melhor o programa na sua dissertação...bem eu sou meio desorganizada... ((pausa))

Mes3-M2-UFCG: quer que eu vá respondendo?

E1-M2-UFCG: você que sabe... 
Mes3-M2-UFCG: bem... os critérios para escolha foram baseados /.../

Tendo em vista que o examinador E1-M2 não tinha se referido, anteriormente, ao procedimento de respostas (se ao final de todas as perguntas ou se após cada uma) e, como após a pergunta citada no exemplo 5, ele fez uma pausa, o mestrando interpretou aquele silêncio como solicitação de resposta. Mas, reconhecendo as características do fato social, que é a defesa e, provavelmente, acionando esquemas cognitivos que indicam respostas ao final das perguntas, o mestrando procura saber se lhe é permitido falar naquele momento ("quer que vá respondendo?"). Recebendo a resposta do E1-M2 (“você que sabe..."), preferiu tomar o turno conversacional e responder.

\subsection{Características formais}

Observando os aspectos macroestruturais do conjunto das defesas que temos registrado, verificamos que ele apresenta os mesmos movimentos retóricos (HASAN, 1994): abertura, defesa propriamente dita, deliberação da banca e encerramento. Cada um desses movimentos compõe-se de vários momentos.

Assim, encontramos cumprimentos, apresentações e instruções para os procedimentos, na abertura; exposição oral do texto-resumo pelo mestrando ou doutorando, agradecimento e questionamento da banca, respostas do pós-graduando, palavras do orientador (comentários sobre o trabalho realizado e sobre o orientando) e solicitação ao público presente (inclusive o pós-graduando) para retirar-se da sala, na defesa propriamente dita; discussão entre membros da banca sobre $\mathrm{O}$ desempenho do pós-graduando, elaboração do parecer conclusivo, na deliberação da banca; e chamada do público para voltar à sala, anúncio do resultado, agradecimento do mestrando ou doutorando, despedida e cumprimentos, no encerramento. $\mathrm{O}$ quadro 3 esquematiza esses movimentos retóricos. 


\begin{tabular}{|l|l|}
\hline MOVIMENTOS RETÓRICOS & MOMENTOS \\
\hline Abertura & Cumprimentos \\
& Apresentações \\
& Instruções para os procedimentos \\
\hline Defesa propriamente dita & Instruções para os procedimentos \\
& Exposição do texto-resumo \\
& Agradecimento e questionamento da banca \\
& Respostas do pós-graduando \\
& Palavras do orientador \\
& Solicitação para saída do público \\
\hline Deliberação da banca & Discussão da banca \\
& Elaboração do parecer conclusivo \\
\hline Encerramento & Chamada do público para voltar à sala \\
& Anúncio do resultado \\
& Agradecimento do mestrando ou doutorando \\
& Despedida \\
& Cumprimentos \\
\hline
\end{tabular}

Quadro 3 - Apresentação dos movimentos retóricos que constituem uma defesa de dissertação/tese

Observamos, nos nossos dados, que o movimento de abertura contém, invariavelmente, os momentos indicados no quadro 3. As apresentações dos membros da banca e do mestrando ou doutorando, feitas pelo orientador, que é o presidente dessa banca, ocorrem com formalidade, mesmo se se trata de professores conhecidos (da mesma instituição ou de outra), conforme podemos ver no exemplo 6.

Ex.6

O4-M2-UFCG: boa tarde... vamos dar início à sessão de defesa de dissertação da mestranda ((cita o seu nome)) de nosso Programa de Pós-graduação em Linguagem e Ensino... a dissertação tem o título 'Reconfiguração do conhecimento sobre produção de texto' /.../ os examinadores são o professor $\mathrm{M}$ da UFPE... da área de matemática e muito envolvido com as questões de transposição didática... e o professor E... do mestrado em Linguagem e Ensino... que também estuda transposição didática... 
Nesse exemplo, constatamos que a apresentação do professor do Programa onde ocorre a defesa (professor E), que era, inclusive, seu coordenador, portanto bem conhecido por alunos e professores, é feita com o mesmo distanciamento que ocorre na apresentação do professor convidado (professor M), que vem de outro programa de pós-graduação (e de outra área) e que não era conhecido pelo público. Tanto são dados os nomes dos professores quanto dos Programas de que fazem parte e suas áreas de interesse acadêmico ("os examinadores são o professor $\mathrm{M}$ da UFPE... da área de matemática e muito envolvido com as questões de transposição didática... e o professor E... do Mestrado em Linguagem e Ensino... que também estuda transposição didática...”). Esse registro linguístico caracteriza a formalidade da defesa, independentemente de ser de dissertação ou de tese.

As instruções para os procedimentos ocorrem tanto na abertura quanto na defesa propriamente dita. $\mathrm{Na}$ abertura, constituem as informações sobre a indicação do local onde podem ficar os membros da banca, durante e após a exposição do pós-graduando e a duração da exposição oral do mestrando ou doutorando (de 20 a 30 minutos). $\mathrm{Na}$ defesa propriamente dita, correspondem à ordem da participação dos examinadores (em primeiro lugar, o convidado externo ao Programa de Pós-graduação e, havendo dois - no caso de defesa de tese -, aquele que vem de mais distante, geograficamente, iniciará a arguição; em seguida o convidado interno tem a palavra para suas considerações e, por último, o orientador faz seu pronunciamento); ao tempo de que dispõe cada convidado para a arguição (em geral, 30 minutos) e igual tempo para o mestrando ou doutorando responder ao que for solicitado; e ao controle do tempo pelo orientador. Podemos ver essas instruções no exemplo 7:

\section{Ex.7}

A) O4-M2-UFCG: /.../vocês ((dirige-se aos examinadores que estão sentados na plateia)) podem ficar onde estão... pra poder ver melhor os slides... depois vocês vêm pra mesa /.../

B) O5-M2-UFCG: /.../ como é de praxe... começando pela professora convidada... professora E.M... que terá 30 minutos para falar e C ((o mestrando)) igual tempo para responder e comentar... 
No exemplo 7A, em que o orientador sugere onde os membros da banca podem permanecer, durante a exposição dos slides, vemos instruções por ocasião da abertura da defesa, antes de o pós-graduando expor seu trabalho. Já no exemplo $7 \mathrm{~B}$, as instruções são dadas no movimento de defesa propriamente dita, antes de cada examinador se pronunciar. É indicado o tempo de que a professora E.M. e o mestrando C. dispõem para sua arguição e respostas, respectivamente.

A exposição oral do pós-graduando é guiada por um texto-resumo escrito e acompanhada por recursos tecnológicos (retroprojetor ou projetor de slides, principalmente esse último), que projetam tópicos relevantes para a compreensão do que está sendo exposto. Encontramos nesses slides, principalmente, título, autor, orientador, questão norteadora da pesquisa, objetivos, tópicos descritivos da metodologia, tópicos de teoria, exemplos de análise e conclusões.

O questionamento da banca é composto por comentários, perguntas e sugestões e, em geral, cada examinador informa como serão dadas as respostas ou feitos os comentários pelos mestrandos ou doutorandos (após toda a intervenção do examinador ou após cada pergunta), como vemos no exemplo 4A e 4B.

Em relação às respostas do mestrando ou doutorando ao questionamento da banca (no movimento retórico de defesa propriamente dita), elas ocorrem, de forma mais recorrente, após todas as perguntas feitas por cada um dos examinadores, como mostra o exemplo 4. Mas podem ser concomitantemente: a cada questão proposta é dada sua resposta ou feito um comentário pelo pós-graduando, como vimos no exemplo 5 , anteriormente.

O momento chamado 'palavra do orientador' corresponde ao pronunciamento do orientador sobre o processo de orientação, o trabalho realizado, a interação do orientador e orientando, entre outros pontos. Ocorre após a arguição dos professores examinadores. Podemos demonstrar esse momento com o exemplo 8, a seguir. 
Ex.8

O5-M2-UFCG: eu vou começar com duas coisas... no geral... agradecer claro a contribuição de B. e de A... A. desde a qualificação que contribui com o trabalho de C... aliás... acho que um pouco antes $/ . . . /$ de fato é... o trabalho de $\mathrm{C}$.... fazendo agora uma paráfrase com o título é produto da minha desorientação ((risos)) porque C. chegou pra fazer o projeto quando ele entrou no mestrado... ele queria fazer uma análise das redações escolares... num era isso C? de um ponto de vista da análise do discurso francesa pra olhar como essas ((incompreensível)) como nossa área é linguagem e ensino... o que isso tem a ver com ensino? então aí apareceu a questão das orientações do professor...

As palavras do orientador correspondem a um relato de como essa dissertação surgiu e das dificuldades que se apresentaram.

Para encerrar esse movimento retórico de defesa propriamente dita, o orientador convida o público a se retirar do ambiente onde ocorre a defesa, para que a banca faça seu julgamento final, o que corresponde ao movimento 'deliberação da banca'. Em discussão restrita aos examinadores e ao orientador, chega-se ao parecer conclusivo, levandose em conta, de modo geral, o percurso acadêmico do pós-graduando, seu envolvimento com a pesquisa, sua análise dos dados e a redação do trabalho final. O exemplo 9 pode ilustrar essa deliberação.

Ex.9

O7-D2-UFAL: solicito que vocês saiam uns minutinhos... para a banca fazer a avaliação final... tomem um café e depois eu chamo... vão pensando nos conceitos ((dirigindo-se aos examinadores, após a saída do público))... o trabalho tá aprovado?... tem que fazer um parecer... preencher a ata... 
A discussão gira em torno da qualidade do trabalho, dos conceitos estabelecidos pelo Programa de Pós-graduação em Letras da UFAL, do desempenho do doutorando, o que contribui para a aprovação final.

No movimento retórico final (o encerramento), o orientador desempenha papel principal: convida o público para voltar à sala de defesa, lê a ata com o parecer da banca e faz algumas recomendações em relação à versão final da dissertação ou tese (sempre há algumas modificações a serem feitas). $\mathrm{O}$ mestrando ou doutorando faz seus agradecimentos e dá-se início ao momento de despedida e dos cumprimentos, encerrando-se a defesa.

Essa descrição da macroestrutura do gênero contribui para que o entendamos como uma ação tipificada, tendo em vista que ela é recorrente em situações análogas. Entretanto, ocorrem particularidades nesse gênero que o tornam diferente e, por algum tempo, estranho. Mas se essa particularidade atende satisfatoriamente ao propósito da ação social, ela passa a constituir característica desse gênero. No item a seguir, abordamos o que é singular, particular, nessas defesas de trabalho de grau, que demonstra a fluidez do gênero.

\section{4 'Defesa' como forma fluida}

Traços singulares foram identificados nas defesas que analisamos: a abertura da defesa estar a cargo da coordenação do Programa de Pósgraduação; a informalidade e descontração promovida pelo orientador; tratamento informal por parte do mestrando ou doutorando em relação aos examinadores; e alteração dos momentos "solicitação para saída do público" (no movimento de defesa propriamente dito) e "chamada do público para voltar à sala" (no movimento de encerramento).

Comumente, cabe ao orientador da dissertação ou tese iniciar a sessão de defesa, no entanto, no M1-UFPB, é o coordenador quem o faz, apresentando fatos recentes do Programa, o mestrando e, às vezes, os membros da banca, como podemos ver no exemplo 10 . 
Ex.10

Co-M1-UFPB: essa semana aqui no Programa graças a Deus a gente tá com uma turma ((incompreensível)) e $80 \%$ da turma vai defender dentro do prazo /.../e aí nesse momento é... é... é... é C.V. ((nome do mestrando)) dizer a ela... desejar boa sorte e dizer que ((incompreensível)) vi compromisso com o Programa... não só da posição de títulos da produção acadêmica de qualidade mas também dentro dos estágios /.../

A abertura da defesa estar a cargo do coordenador do Programa de Pós-graduação (função mais alta na hierarquia do Programa) confere a esse fato social mais formalidade, pois esse coordenador não constitui membro integrante da banca, nem presenciará a defesa. Se, por um lado, esse procedimento imprime maior importância ao fato, por outro, pode ocasionar alguns inconvenientes, tais como o atraso da abertura. Foi o que aconteceu na defesa a que o exemplo 10 se refere: seu início estava previsto para as nove horas, mas só ocorreu às dez horas, momento em que o coordenador chegou à sala de defesa, após ter procedido à abertura de outras que estavam acontecendo.

Em relação ao item formalidade, constatamos que à abertura formal que caracterizou sete das defesas analisadas contrapõe-se a abertura da defesa de tese do Programa de Pós-graduação da UFPE. Realizada de forma descontraída e humorística, foi apresentado o título da tese, o doutorando e foi informado o tempo (30 minutos) de que ele disporia para expor seu trabalho. A descontração da abertura caracterizou todo o conjunto de movimentos retóricos da defesa, que foi permeada por risos, dispensa de formalidades no tratamento dados aos membros da banca e ao público. Podemos ilustrar essa descontração com o exemplo 11, que mostra a participação do orientador e de um examinador externo ao Programa de Pós-graduação em Letras (que era estrangeiro): esse, após longa explanação teórica e já tendo ultrapassado os 30 minutos que the foram determinados, fez uma pergunta ao doutorando, que recebeu o turno de uma maneira inusitada. Vejamos o exemplo 11. 


\section{Ex.11}

E1-D3-UFPE: /.../ e... bem... é... que já basta... não dá mais tempo... é... terás que ter uma pergunta... os gêneros se ensinam? é... e vou colocar uma segunda... por que é que os gêneros devem ou não devem ensinar-se?

O3-D3-UFPE: sim senhora...

Dou3-D3-UFPE: bom... a observação da professora que... que... a ação pedagógica [...] que o gênero aponta para uma ação pedagógica /.../

A formalidade com que E1-D3 vinha discorrendo sobre gênero e seus aspectos sociais e cristalizados e anuncia as perguntas dirigidas ao doutorando (faz a primeira pergunta e, através do recurso da metalinguagem, informa que vai fazer a segunda: "os gêneros se ensinam? [...] é... e vou colocar uma segunda... por que é que os gêneros devem ou não devem ensinar-se?") é quebrada com o turno do orientador, passando a palavra ao orientando (O3-D3): "sim senhora...". Essa frase, dita com riso, tanto pode ser interpretada como uma aprovação do que fora dito por E1-D3 quanto como a indicação de que a partir daquele momento o orientando estava sendo desafiado e deveria falar, respondendo às perguntas feitas. Tanto é um desafio, que a orientanda hesita, interrompe o turno, reformula-o, até conseguir organizar sua resposta.

Ainda em relação à defesa referida no exemplo 11, outro ponto que alterou a tipificação do gênero foi, no final do movimento retórico 'defesa propriamente dita', o orientador solicitar ao público que permanecesse na sala, pois quem se retiraria seria a banca examinadora. Nas palavras do orientador, a orientanda "inaugura novo modo". Isso causou inclusive um burburinho entre os presentes, estranhando aquela atitude: "por que a banca sai?" O que foi que aconteceu?", ao que o orientador respondeu: "porque vocês são maioria e a banca é minoria."

A informalidade por parte do orientador também foi identificada no M2-UFCG, no momento do anúncio do resultado (no movimento de encerramento), após o público ter voltado à sala de defesa, como comprova o exemplo 12. 
Ex.12

O3-M2-UFCG: ((membros da banca em pé, para ser dado o parecer final)) antes de ler o parecer... E. ((nome do mestrando)) onde estão meus livros? devolva todos senão... não libero seu título ((risos de todos)) / ... / a banca reunida deliberou o seguinte parecer ((lê a ata com o parecer dado, aprovando o mestrando))

A solicitação dos livros, no momento em que se esperava o parecer final, constituiu uma quebra de protocolo de tal forma que provocou risos da banca e do público. Mas deixou o mestrando um tanto constrangido, pois se sentiu instado a informar a data de sua devolução (o que o fez, tão logo o orientador cedeu-lhe a palavra).

Chamou-nos a atenção também a interação entre doutorando e examinadores, especificamente nas formas de tratamento. Embora se tratasse de uma situação comunicativa formal, tensa, os candidatos tratavam pelo nome próprio, sem nenhum título, os examinadores conhecidos e pelo título "professor/a" aqueles menos conhecidos. Isso demonstra que a relação interpessoal afeta o gênero defesa de trabalho de grau, favorecendo a descontração e a familiaridade e neutralizando a fronteira entre o público e o privado; é o que vemos no exemplo 13, abaixo.

\section{Ex.13}

A) Mes1-M1-UFPB: EM. já tinha dito isso ((refere-se ao membro da banca, pertencente ao Programa de Pós-graduação a que o mestrando está vinculado)).

B) Mes3-M2-UFCG: nesse caso aí... D ((nome do orientador)) a professora tem um papel importante... porque a professora julgava... escolhia o material /.../

C) Dou1-D1-UFPB: é... M ((nome de examinador do próprio Programa)) isso mesmo que ocorre /.../

D) Mes2-M2-UFCG: não professor... estou chamando reconfiguração o processo de adaptação dos conhecimentos /.../ 
Os exemplos 13A, B, C referem-se a professores com quem os mestrandos e doutorandos têm contato ora como alunos ora como amigos, enquanto 13D, ao professor de outro Programa de Pósgraduação, convidado para participar da banca e não conhecido pelo mestrando. Daí o distanciamento e o uso da palavra "professor", não acompanhada pelo nome próprio desse professor.

Essas formas singulares constituem índices de que os gêneros, embora tipificados, são flexíveis.

\subsection{Gênero 'defesa' sem determinante}

Observando todos os dados que temos, percebemos que a defesa de dissertação ou de tese não apresenta diferenças que a caracterizem como dois gêneros diferentes. Seus usos sociais, as interações realizadas no ato de comunicação e os itens formais delas decorrentes apontam para uma ação social do meio acadêmico chamada 'defesa'. Tanto é que os participantes dessa ação fazem referência a ela utilizando-se da palavra 'defesa' sem os sintagmas 'de dissertação' ou 'de tese'. Em nossos dados, identificamos turnos conversacionais do público ouvinte, formulados assim: "a defesa foi muito boa"; "a defesa de ((nome do pós-graduando)) vai ser semana que vem".

Se, conforme afirma Marcuschi (2005, p. 19), os gêneros "não deixam de ser sensíveis à realidade de seu tempo e profundamente envolvidos com as diversas formas de comunicação existentes", sua denominação vai refletir esse envolvimento. Considerando que Programas de Pós-graduação preveem a elaboração de uma dissertação, no curso de mestrado, e de uma tese, no curso de doutorado, deduzimos que dissertação e tese são gêneros diferentes, que funcionam em situações específicas, com objetivos diversificados. Podemos afirmar que são trabalhos de grau acadêmico: grau de mestre e de doutor, respectivamente. Logo, a expressão 'trabalho de grau' superordena os gêneros dissertação e tese, uma vez que ambos constituem ações da academia, fazem parte de sistemas de gêneros e podem ser referidos como exemplos de trabalho realizado para atender às exigências de um mestrado e de um doutorado. 
No entanto, a exposição oral desses trabalhos, para uma banca julgadora, com o intuito de demonstrar a importância do estudo feito, funciona socialmente com as mesmas formas de agir e buscando-se os mesmos efeitos, que são a aprovação e a obtenção de um título. A descrição que fizemos neste artigo mostra que as ações são idênticas, tanto é que, ao nos referirmos aos autores dos trabalhos, utilizamos 'mestrando' e 'doutorando' ao mesmo tempo, ou o hiperônimo 'pósgraduandos'. Agimos assim, orientada pelos dados disponíveis, nos quais não se percebem traços específicos de uma defesa de dissertação ou de uma tese, salvo quando é anunciado pelo orientador, como podemos ver no exemplo 14.

Ex.14

A) O7-D2-UFAL: vamos dar início à defesa da tese de F. ((cita nome do doutorando)), intitulada 'uma leitura sociointeracionista do gênero piada na oralidade'...

B) O1-M1-UFPB: bom dia... pelo jeito nós... a... a... a... estamos sendo privilegiados né? ((incompreensível)) por termos essa plateia e esse espaço /.../ então C ((nome do mestrando)) nos reúne aqui hoje né... com o seu trabalho com sua dissertação 'alfabetização de adultos e idosos: novos horizontes' / ... /

Nas aberturas de defesas mostradas em 14A e 14B, identificamos o uso dos substantivos 'tese' e 'dissertação', não fazendo parte do nome do gênero defesa, mas acompanhado do nome do autor, determinando 'tese' ("defesa da tese de F"), em 14A, e do título ("alfabetização de adultos e idosos: novos horizontes”), especificando 'dissertação', em 14B. Esses exemplos representam casos recorrentes em nossos dados, o que nos leva a afirmar que o gênero em questão é 'defesa'.

Assim, o que está em evidência é a defesa e não a dissertação ou a tese, visto que ambas, necessariamente, vão ao julgamento. Daí o uso pelos participantes de Programas de Pós-graduação do termo 'defesa', sem os determinantes 'de dissertação' e 'de tese'. Se, em algum momento da história, a identificação desses trabalhos foi necessária, essa motivação parece ter-se perdido. 


\section{CONSIDERAÇÕES FINAIS}

A descrição feita demonstra ser a defesa um gênero. A análise aponta tanto a presença de formas tipificadas idênticas, tais como ações sociais próprias de Programas de Pós-graduação, incluídas em um conjunto de gêneros que funcionam nesse ambiente social; traços formais como exposição de texto-resumo, questionamentos, respostas; quanto a de dados singulares em defesa de dissertações e de teses, por exemplo, situação distensa, informalidade e uso de palavras denotando aproximação. Essas singularidades identificadas dependem mais dos participantes da interação social onde ocorre a defesa do que da ação social de defesa de trabalho em si mesma.

Considerando a linguagem utilizada pelos atores envolvidos nessa interação social, notamos que, do ponto de vista da argumentação, os examinadores não se utilizam de recursos linguísticos que denotem imposição e exigência de respostas. Mesmo que a situação comunicativa preveja essa ação, os arguidores lançam mão de palavras atenuadoras (como "talvez fosse interessante você responder..."), minimizando a ameaça feita à face do mestrando/doutorando. Isso sugere que a formalidade que envolve a defesa pode ser interpretada pelo examinador como suficiente para que os pós-graduandos sejam impelidos a responderem às questões que lhes são feitas (ainda que o ato de fala tenha sido mitigado, dando-lhes a possibilidade de não atender ao solicitado).

Além disso, a defesa, sendo um gênero oral e formal, comporta, como características linguísticas, expressões ou palavras que reforçam a distância entre banca e pós-graduando. E, assim, o uso de formas linguísticas que venham diminuir essa distância pode representar uma quebra de expectativa por parte dos envolvidos com esse gênero.

Dado que não percebemos usos ou formas que determinem ser a defesa de dissertação diferente da defesa de tese, defendemos ser um só gênero (defesa). A especificação "de dissertação" ou " de tese" reflete os gêneros escritos, assim reconhecidos, que originam a defesa oral de trabalhos de grau, expressão superordenada, que faz referência aos gêneros dissertação e tese, que são escritos. 


\section{REFERÊNCIAS}

BAZERMAN, C. Gênero, agência e escrita. HOFFNAGEL, J. C.;

DIONISIO, A.P. (Orgs.). São Paulo: Cortez, 2006.

Gêneros textuais, tipificação e interação. DIONISIO, A. P.;

HOFFNAGEL, J.C. (Orgs.). São Paulo: Cortez, 2005.

HASAN, R. Situation and the definition of genres. In: GRIMSHAW, A. D.

(Org.). What's going on here? Complementary Studies of Professional Talk.

Norwood: Ablex, v.2, 1994, p. 127-172.

MARCUSCHI, L.A. Gêneros textuais: configuração, dinamicidade e circulação. In: KARWOSKI, A.M.; GAYDECZKA, B.; BRITO, K.S. (Orgs.). Gêneros textuais: reflexões e ensino. Palmas e União da Vitória, PR: Kaygangue, 2005, p. 17-33.

MILLER, C. Blogging as Social Action: a genre analysis of the weblog. Into the blogosphere. 2004. Disponivel em:

<http://blog.lib.umn.edu/blogosphere> . Acesso em: ago. 2007.

. Rhetorical Community: The Cultural Basis of Genre. In:

FREEDMAN, A.; MEDWAY, p. (Eds.). Genre and the New Rhetoric.

London/Bristol, Taylor \& Francis, 1994, p. 67-78.

1984.

Genre as social action. Quarterly Journal of Speech, n.70, p. 151-167,

\section{ANEXO A}

Títulos das dissertações e teses cujas defesas foram analisadas:

M1-UFPB: A alfabetização de adultos e idosos: novos horizontes. Programa de Pós-graduação em Educação, 2006.

M2-UFCG: Apropriação da escrita acadêmica por professor em formação e implicações na sua prática pedagógica. Programa de Pós-graduação em Linguagem e Ensino, 2006.

M3-UFCG: Reconfiguração do conhecimento sobre produção de texto: da linguística à prática da sala de aula. Programa de Pósgraduação em Linguagem e Ensino, 2006. 
M4-UFCG: O processo de transposição didática no jornal e na escola. Programa de Pós-graduação em Linguagem e Ensino, 2006.

M5-UFCG: Escolhas lexicais em redações escolares como produto de orientações para o ensino de produção escrita. Programa de pós-graduação em Linguagem e Ensino, 2006.

D1-UFPB: A didatização do conceito de leitor competente: dos PCN-LP ao leitor construído em aulas de leitura. Programa de Pós-graduação em Letras, 2006.

D2-UFAL: Uma leitura sociointeracionista do gênero de texto 'piada' na oralidade. Programa de Pós-graduação em Letras, 2006.

D3-UFPE: Parecer pedagógico: um gênero construindo a prática docente. Programa de Pós-graduação em Letras, 2006.

\section{ANEXO B}

As transcrições dos dados gravados seguiram normas do Projeto NURC, utilizadas nos trabalhos de análise da conversação:

\begin{tabular}{|l|l|l|}
\hline Ocorrências & Sinais & Exemplificação* \\
\hline Entoação enfática & Maiúsculas & ...vamos ter DEZ defesas... \\
\hline Qualquer pausa & $\ldots$ & bom...primeiro... \\
\hline Pergunta & $?$ & o que são essas categorias? \\
\hline Comentários descritivos do transcritor & $(())$ & $($ (risos)) \\
\hline Corte no trecho transcrito & $/ \ldots /$ & $/ \ldots /$ diz que há simulação... \\
\hline
\end{tabular}

$*$ Exemplos retirados do material transcrito.

Recebido em 30/08/2010. Aprovado em 20/11/2010.

Title: Description of the genre "defense" of academic work: typification and singularity Author: Maria Auxiliadora Bezerra

Abstract: The aims in this paper are to describe the genre of defense of academic works, identifying typified forms that are characteristic of the defense of dissertations and theses, and to demonstrate that they do not constitute different genres, since identical behaviors are displayed in order to reach the same goals: to acquire an academic title. Thus, under the perspective of the socio-rhetorical studies andio recordings of eight defenses were analyzed, as well as the answers from professors and graduate students to the question "What is a defense of a thesis/dissertation?" The analyses showed the presence of identical 
typified forms (as the exposition text-summary, questioning, answers), and singular data (relaxed situation, informality and the use of words showing proximity), allowing one to make some conclusions: "defense of a graduation work" may be used as a superordinate phrase; singularities depend more on the participants in the social interaction in which the defense takes place, than on the social action of the defense of the work, while the specification "dissertation/thesis" reflects the written genre, which originate its oral defense.

Keywords: Genre. Dissertation. Thesis. Defense.

Descripción del género "defensa" de trabajos de graduación: tipificación y singularidad

Autor: Maria Auxiliadora Bezerra

Resumen: Los objetivos de este articulo son describir el género defensa de trabajos, identificando formas tipificadas, características de defensa de disertación y de tesis, y demostrar que no se constituyen géneros diferentes, pues son retomadas formas de actuar idénticas, esperando obtener los mismos efectos: obtención de título académico. Para eso, analizamos, a la luz de estudios sociorretóricos, ocho defensas audiograbadas y respuestas de profesores y de pósgraduados a la pregunta "ZQué es defensa de disertación/tesis?". Los análisis demuestran presencia de formas tipificadas idénticas (como exposición de texto-resumen, cuestionamientos, respuestas) y datos singulares (situación distensa, informalidad y uso de palabras denotando aproximación), posibilitando algunas conclusiones: "defensa de trabajo de graduación" puede ser utilizada como una expresión superordenada; singularidades dependen más de los participantes de la interacción social donde ocurre la defensa de que de la acción social de defensa de trabajo y la especificación "disertación"/ "tesis" refleja los géneros escritos, que originan su defensa oral. Palabras-clave: Género. Disertación. Tesis. Defensa. 